\title{
Expert yet vulnerable: Understanding the needs of transit dependent riders to inform policy and design
}

\begin{tabular}{cl}
\hline Emma J. Rose & $\begin{array}{l}\text { University of Washington Tacoma, USA } \\
\text { Corresponding Author. } \\
\text { ejrose@uw.edu }\end{array}$ \\
Robert Racadio & University of Washington, USA \\
& $\underline{\text { racadio@uw.edu }}$ \\
EMC, USA & travis.martin@emc.com \\
Travis Martin & USA \\
Deidre Girard & $\underline{\text { deidregirard@gmail.com }}$ \\
University of Washington, USA & $\underline{\text { bkolko@uw.edu }}$ \\
\end{tabular}

Transportation is a crucial resource that links people to jobs, social networks, community and services. The transit dependent -- those who do not own private vehicles -- occupy a unique position. They are expert in their knowledge of public transportation while vulnerable to the failures and limitations of transit. This paper presents the results of a study that is aimed at understanding the lived experience of transit dependent riders. Using a framework of structuration theory as an analytic lens, we provide a thematic analysis of qualitative data including interviews with socially connected groups of people and video diaries. The results demonstrate the expertise that transit dependent riders have about transit and its policies and how they deploy that expertise in

Rose, E., Racadio, R., Martin, T., Girard, D., Kolko, B. (2017). Expert yet vulnerable: understanding the needs of transit dependent riders to inform policy and design. The Journal of Community Informatics, 13(1), 3-24.

Date submitted: 2015-08-21. Date accepted: 2017-03-18.

Copyright (C), 2017 (the authors as stated). Licensed under the Creative Commons AttributionNonCommercial-ShareAlike 2.5. Available at: www.ci-journal.net/index.php/ciej/article/view/1262 . 
productive and cunning ways to make the system work for them. The analysis of this data resulted in three categories of agency to consider when designing for vulnerable populations: resourcefulness, reciprocity and powerlessness. The paper concludes by advocating for a human-centered approach to designing systems in community informatics and offers a set of guiding questions for designers of information and communication technologies (ICTs) to consider, especially with regards to vulnerable populations.

\section{Introduction}

Transportation is a crucial resource that links people to jobs, social networks, community and services. The research described in this paper investigates the experience of people who are transit dependent, that is, people who do not have access to private vehicles and therefore use public transportation as their primary mode of transit. The study aim was to identify the ways in which information and communication technologies (ICTs) are designed - and could be designed differently - to take into account the needs of transit dependent riders.

The field of community informatics has focused primarily on how to improve equity and work for social justice through ICTs, specifically how they are accessed, designed and encourage participation. We are inspired by recent work on expanded urban planning, a concept that positions people and their local knowledge as valuable and necessary (Staffans \& Horelli 2014). We situate this study to engage in issues of participation and inclusion in the design of ICTs; we are specifically interested in how vulnerable populations are engaged or excluded. We add to the voices that hope to problematize the notion of the digital divide and agree that the digital divide is often too narrowly focused on issues of technology access (Gurstein 2015). In this work, we go beyond issues of access to consider and examine how the design of information and communication technologies affect vulnerable groups like transit dependent riders and how paying attention to these vulnerable groups privileges different needs, concerns and issues related to public transportation and urban infrastructure.

As a field, community informatics has always been interested in ways that ICTs are made available, designed and used to explore and support people's needs. According to Gurstein, community informatics examines "how and under what conditions ICT access can be made usable and useful, that is, how "effective use" can be achieved by, among others, marginal or excluded populations and communities" (2003, p 44). In our work, we agree that ICT access is important but we go further to review the design of the ICTs and how the design enables and constrains use. As ICTs become more embedded and invisible, community informatics scholars and activists should question how design decisions are made, by whom, and for whom, and as a result, whose needs are overlooked or obscured. Therefore it is valuable to examine the manner in which ICTs have been designed and to look at the resulting impact of that design. In addition, looking for ways to include more people in the design process provides an opportunity to 
consider the methods and techniques in our field that invite and stimulate collaboration and participation.

Our focus on the transit dependent rider is motivated by a commitment to social justice, but also because these riders fill a unique space in the transit ecosystem. They are experts of the system and have a sophisticated understanding of its nuances, while still occupying a vulnerable position where changes to the system can disproportionately and negatively affect their lives. The vulnerability of transit dependent riders reflects inequities present in American society. People who are transit dependent are more likely to be a member of a minority group (Garrett \& Taylor, 1999). This further amplification of inequities makes discussions about transportation policies and planning political ones: the search for transit equity is related to civil rights and social justice (Bullard, 2003). While transit dependent groups tend to be the largest users of transportation, their needs are often overlooked or are secondary to what is commonly referred to as "choice riders," meaning riders who can choose between using public transportation vs. a private vehicle (Garrett \& Taylor, 1999). Looking at transportation and its supporting ICTs from the experience and perspective of transit dependent riders can uncover ways in which design choices have unintended consequences for the transit dependent.

The purpose of this article is to examine the lived experience of people interacting with public ICTs in order to examine how design reinforces existing inequities and how individuals attempt to exercise their expertise to overcome structural constraints. Specifically, we look at the space of transit dependent riders and the ICTs supporting public transportation. First, in this paper, we explore the intersections between design and community informatics, then we review the concept of transit dependence in more detail and the theory of structuration. Second, we explain in detail the study methods used to investigate the transit dependent experience. Third, we provide three categories of agency developed from the study data with examples from the data. Fourth, we discuss and apply the theoretical framework of structuration to the findings in order to critique transportation ICTs and identify future design opportunities. Finally, we conclude with a call for a participatory human-centered design approach to the design of ICTs in the public sector.

\section{Investigating transportation through structuration}

In this section, we provide additional background for transportation ICTs and the groups of people who are affected by their design. First, we start with a discussion of the concept of transit dependence. Then we explore the principles of Giddens's structuration theory, how it applies to the study of transit systems and acts as a lens for the design of our empirical study.

\section{Transit dependence}

The people who use public transportation are commonly divided into two groups: transit dependent and choice riders (Polzin, Chu \& Rey, 2000; Beimborn, Greenwald \& Jin, 2003; Krizek \& El-Geneidy, 2007). Transit dependent riders are people who rely on public transportation and do not own private vehicles. This group is also often referred to as "captive" 
riders. The second group -- choice riders -- are people who own or have access to a vehicle but choose to use public transportation. Distinguishing transit dependence from choice ridership helps to clarify how creators of transit systems and services conceptualize their audiences, and also helps shed light on the values that are embedded, explicitly or implicitly, by this categorization. The transit dependent group is captive to their limited transit options, whereas choice riders have more freedom to choose between public and private transit. More attention is usually given to choice riders to entice them to take public transit. As a result, the transit dependent audience's needs may be of secondary importance, even though this group tends to be more vulnerable and has less power.

Lacking access to transportation intensifies some of the challenges that the poor confront. Studies have shown that reliable access to transportation is a key to alleviating poverty (Booth, Hanmer, \& Lovell, 2000; Sanchez, 2008). Several studies identified that car ownership is predictive of people transitioning from public assistance to employment, a phenomenon also referred to as "driving out of poverty" (Brabo, Kilde \& Pesek-Heeriges, 2003; Taylor, 2009). In addition, limited transportation options reduce access to healthcare and negatively affect health (Rittner \& Kirk, 1995). Transportation also plays a crucial role in maintaining and improving social networks, and a lack of access to social networks leads to a lack of social capital (Bradbury, 2006). A variety of researchers have called for improvements to transportation policies, services and schedules that would benefit people who are transit dependent in order to improve equity. Ferguson and others propose a new way to design transit routes that provide transit dependent riders access to basic amenities such as employment, supermarkets, medical service (Ferguson et al. 2012). In addition to providing access to amenities, research by Giuliano proposes changes to transit routes, including expanding service to underserved markets and increasing service during off-peak and off-direction commutes, to improve access and mobility for low income transit riders (Giuliano, 2005).

When looking at the crucial role that transit plays in the lives of economically vulnerable individuals and families, it is valuable to look for creative solutions that are feasible within current service offerings. It may not be possible to increase service and routes or provide private vehicles to help individuals move out of poverty. Instead, we propose thinking about ways to improve the design and development of ICTs within the existing transit system architecture to lessen the challenges and constraints of the transit dependent. For example, more transit agencies are providing real-time transit information that can be accessed on mobile devices by integrating it into their online services or making the data available to third parties who build interfaces to access this information such as Google maps (https:/www.google.com/maps/) and One Bus Away (Ferris, Watkins and Borning, 2010a). Real time data can improve the rider experience by increasing rider satisfaction, minimizing wait times, and improving perceptions of safety (Ferris, Watkins and Borning, 2010b). Typically, ICTs are designed to accommodate the entire rider population and they can potentially improve the transit experience for all riders. 


\section{Structuration theory and transit}

To examine the relationship between riders and the transit system, we employ structuration, a macro-sociological theory that explains how societies change over time (Giddens 1984). Central to this theory is the concept of duality between structure and agency. According to Giddens, social action creates and recreates society and structure. Actors make choices based on rules and resources, and their actions both create and reinforce the structure of society. The relationship is recursive: structure enables and constrains actions, and actions reinforce and shift structure.

While structuration theory operates at a macro level to describe how societies change over time, looking at a specific time and context can explain the ways in which the duality of structures and agents are in play. Structuration has been applied in a variety of disciplines and fields to understand the relationships between structure and actors. In urban studies, structuration has been used to examine neighborhood decline (Aalbers, 2006), the coordination of trips in cities (Pratt, 1996), and to evaluate the role of organizations within communities (McQuarrie and Marwell, 2009). Using structuration to look at transportation provides a way to examine the relationships between structures, including institutions, rules, and resources, and the actors who are negotiating the system to bring about the desired end result

In our research, we examine how agency is enabled and constrained by the transit system. By looking at the agentive acts of individuals, we can evaluate how a structure is designed and implemented and in turn imagine alternatives. Giddens refers to actors as "knowledgeable agents," meaning that they can reflect and act purposefully within the ongoing flow of social life. Agents' knowledgeability allows them to navigate and make choices in the social world, and is exhibited in two ways. First, through discursive consciousness, which is an individual's ability to talk about his or her actions, intentions and reasons. Second, through practical consciousness, or the knowledge and practices that individuals might not be able to express discursively. Giddens refers to practical consciousness as "what is simply done." What is essential to this framing of knowledgeability is that humans are purposeful, reflective actors in the world. However, while humans know and explain what they are doing, they may "know little of the ramified consequences of the activities in which they engage" (Giddens, 1986, p.14).

The notions of agency and structure in structuration theory provide a framework for taking the experiences of transit dependent riders seriously. It provides a basis for understanding the structures of transit as well as how agency and power are wielded within the system. Structures of transit - transit authorities or organizations that make decisions on fares, routes, policies, schedules and services - enable and constrain the actions that people take while riding transit such as the embedded expectations of behavior and activities while riding transit. The knowledgeable agents - the transit dependent riders - in our study demonstrate how they are both constrained and empowered by these structures through their stories and practices. By conscious attention to these tensions in the duality between structures and actors, we can observe the ways that the systems can be designed differently and improved. Our goal is to position the design of ICTs as an intervention that can support the needs of both transit agencies and transit dependent riders. 


\section{Research design and methods}

In this section, we describe the research environment and the study participants. We then describe our methods for data collection and analysis. The study design, informed consent processes, and methods were reviewed and approved by the University of Washington's Institutional Review Board.

\section{Context of the research site}

We conducted our study at White Center, an urban neighborhood south of Seattle, Washington, which we chose for its diverse community and location. $27 \%$ of the population in White Center is foreign-born, and $36 \%$ of the residents live $200 \%$ below the poverty line. As a transit hub, White Center is an appropriate location to investigate the needs of transit dependent riders.

The data for this study was collected in 2010. At that time significant changes were happening within the local transportation system. The changes included substantial service reductions due to budget constraints brought on by economic recession. The cut in funding for services translated to fewer buses and bus routes, at the same time that more people were becoming transit dependent because of the economic decline. The local transit agency was promoting a new smart card system and allowing electronic payments with the aim of phasing out paper bus transfers.

We return to this data now to apply and use structuration as a lens through which to view policy and societal shifts. By focusing on change events such as policy and ICT interventions, we can see how structures enable and constrain the actions of agents. This viewpoint provides a productive way to examine the impact of policy and ICT changes. As transportation options and the freedom to move around become constrained, the design of ICTs can be updated and improved to help people make more efficient use of an increasingly scarce resource.

\section{Data collection}

In this study, the research team collected data using a variety of qualitative research methods including ethnographic observation, semi-structured interviews, and video diaries. We deployed design ethnography, a holistic research strategy that supports the examination of the situated actions that people perform and the tools they use. The richness of ethnographic data, which reflects the practices of people in the greatest possible context, helps designers create products for appropriate audiences (Salvador, Bell \& Anderson, 1999).

To capture the experience of the transit dependent, we gathered a variety of ethnographic data including observing, documenting, and photographing the daily rhythms of bus riders in White Center (Rose 2011) and conducting autoethnographies (Anderson, 2006) of our own transit experiences as an act of defamiliarization (Bell, Blythe, \& Sengers, 2005). We spoke informally with community members in libraries, cafes and community centers about the challenges they face related to transit. Later in the study, we took part in participant observation (Atkinson and Hammersley, 1994), including riding along with interview participants, to gain a deeper 
understanding of daily lives of transit dependent riders. To record this data, the team took field notes and photographs and wrote reflections.

To understand the challenges and lived experience of transit dependence, we conducted interviews with socially connected groups of transit dependent riders. We recruited participants through flyers posted around the neighborhood, including transit centers, libraries, community centers and bulletin boards. We screened and selected participants based on factors including car ownership and frequency of transit use. Out of the group of people who volunteered for the study, we selected participants to achieve diverse representation across gender, age and ethnicity. Participants were invited to bring friends or family members to take part in the interviews. Talking to groups of socially connected people allowed us to understand the social context of transportation choices and usage. Participants described their transit patterns of use, reflected on challenges and current practices, and identified opportunities or areas for improvement. Each participant received a $\$ 20$ honorarium for taking part in the interviews.

In total, we spoke to six groups of people, with groups ranging in size from two to five people, for a total of 15 participants overall. Depending on whether they also participated in our video diary activity, we spoke with each group between one and four times. We met participants at locations of their choosing, including coffee shops, community centers and private homes.

At each group interviews, we asked for volunteers to participate in a follow up activity. We gave video cameras to this subset of participants and asked them to create video diaries of their transportation experiences. This video data collection is a variation of photovoice (Chavez, 2004; Wang \& Burris, 1997). Giving participants cameras is a participatory research method that encourages them to guide the research collection and focus on what they think is significant. After the participants created their videos, we met with them to watch the videos together and conducted a follow-up interview. The participants in this activity were given the camera as an honorarium. Details about the participants and their pseudonyms are listed in Table 1. 
Table 1. Overview of research participants in White Center/Seattle

\begin{tabular}{|c|c|}
\hline Group number, description, & $\begin{array}{l}\text { Participants from group interviews } \\
\text { (all names are pseudonyms) } \\
*=\text { also participated in video diaries }\end{array}$ \\
\hline $\begin{array}{l}\text { Housemates: } \\
\text { 1. Two middle-aged men living in a recovery } \\
\text { facility }\end{array}$ & $\begin{array}{l}\text { - } \text { Eddy* } \\
\text { - Shawn }\end{array}$ \\
\hline 2. Younger couple with school-aged children & $\begin{array}{l}\text { - } \\
\text { - } \\
\text { Brian }\end{array}$ \\
\hline 3. Married middle-aged couple & $\begin{array}{ll}\text { - } & \text { Adam* } \\
\text { - } & \text { Rachel }\end{array}$ \\
\hline 4. Older woman and her niece who lived together & $\begin{array}{l}\text { - Helen* } \\
\text { - Monica* }\end{array}$ \\
\hline $\begin{array}{l}\text { 5. Group of friends. Middle-aged and older adults; } \\
\text { all were homeless }\end{array}$ & $\begin{array}{ll}\text { - } & \text { Louis } \\
\text { - } & \text { Ryan } \\
\text { - } & \text { Cynthia } \\
\text { - } & \text { Stephen } \\
\text { - } & \text { Timothy }\end{array}$ \\
\hline 6. Roommates in their early $20 \mathrm{~s}$ & $\begin{array}{ll}\text { - } & \text { Joey } \\
\text { - } & \text { Gabe }\end{array}$ \\
\hline
\end{tabular}

\section{Data analysis}

Data collection occurred over three months. The ethnographic data provided a background for the research site and framed the resulting interviews and video transcripts. The research team followed standard qualitative research coding techniques to identify codes and categories (Coffey \& Atkinson 1996) using the collaborative web-based tool Saturate (http://www.saturateapp.com). We coded speech at the phrasal level. The transcripts were coded by five team members. For inter-coder reliability, each transcript was coded by at least two researchers. Categories were named and negotiated by the five-person team during weekly analysis meetings. Codes were also assigned and adjusted by individuals analyzing the data and during team meetings where codes were adjusted based on group consensus. Based on the theoretical framework of structuration, the research team coded for agentive acts and structural constraints to look for ways the transportation systems and supporting ICTs were enabling and constraining action. 


\section{Study findings: Categories of agency for transit dependent riders}

Observing and interviewing public transit riders gave us insight into the lived experience of the transit dependent. Using a structuration framework, we focused our analytical attention on acts of agency and how these actions were enabled or constrained by a variety of structures. Since our primary attention was on the actors, we categorized their agentive acts into three themes: resourcefulness, resilience and powerlessness. Table 2 shows a summary of the three categories, their definition and a selection of findings from the study. In the following section, we define each theme and present evidence in the form of quotes from participants in the study.

Table 2. Summary of findings

\begin{tabular}{|l|l|l|}
\hline Category & Definition & Example \\
\hline Resourcefulness & $\begin{array}{l}\text { Deploying expertise to resolve } \\
\text { structural constraints in ways that } \\
\text { are sanctioned and productive }\end{array}$ & $\begin{array}{l}\text { Grouping errands together to } \\
\text { maximize a free transfer } \\
\text { Supplementing official transit } \\
\text { information with prior } \\
\text { knowledge } \\
\text { Taking mini-vacations via transit }\end{array}$ \\
\hline Resiliency & $\begin{array}{l}\text { Manipulating structures or } \\
\text { resources to overcome barriers, in } \\
\text { unsanctioned or unanticipated } \\
\text { ways }\end{array}$ & $\begin{array}{l}\text { Taking extreme measures like } \\
\text { biking or walking far distances to } \\
\text { accommodate limitations of the } \\
\text { transit system }\end{array}$ \\
\hline Powerlessness & $\begin{array}{l}\text { The inability to overcome } \\
\text { structural constraints }\end{array}$ & $\begin{array}{l}\text { Fare evasion } \\
\text { Losing a job because the bus was } \\
\text { late } \\
\text { Safety concerns }\end{array}$ \\
\hline
\end{tabular}

\section{Resourcefulness}

Resourcefulness, as we define it here, means making choices to make the best of the transitdependent experience. A key distinction of resourceful acts is that they are sanctioned and within the norms of acceptable transit use. Within these norms, actors deploy their extensive expertise of the transit system to find creative solutions to problems and to make trips easier and more enjoyable.

As regular users of public transit, the study participants deployed their expertise to choose an optimal route that was based on personal criteria beyond transit time and walking distance. Riders knew the fine points of the system, the routes, when to ride, and where to transfer. They knew which routes were fast or slow, pleasant or unpleasant, or safe or dangerous. When 
planning their day, riders often included a considerable amount of extra time for their commute, taking earlier buses to ensure that they arrived at locations on time, especially when the trip was for work or doctor appointments. Some riders optimized their trips by grouping errands that coincided with particular bus routes, and then used any extra time on a transfer ticket for unplanned errands or leisurely activities. Riders frequently supplemented the available transit resources, such as online trip planners, with knowledge gained through their own experiences. For example, one rider mentioned a trip from a place in southwest Seattle to a place in southeast Seattle. The trip planner recommended a route that went north to downtown, only to return southward, instead of suggesting a 10-minute walk eastward to catch a different bus with a more direct route. As one participant said, "I am aware of the limitations of the trip planner, so I tweak the system."

Some riders take the bus as a form of recreation, relaxation, and refuge. Riding the bus without a concrete destination in mind, these riders explore new neighborhoods, learn the layout of the city, or pass the time. This leisurely riding is seen as a form of cheap entertainment. Several riders mentioned the practice of taking a trip to "find out what was at the end of the line". Others riders choose routes that were based on the scenery, occasionally taking longer trips to enjoy a more relaxing ride. The idea that a bus could be a refuge or sanctuary came up with the group of homeless participants. One rider said, "There is a lot of chaos downtown. There's chaos on buses too, but on buses I don't have people coming up to me asking to buy dope or drinking. I can listen to my CD player and just ride the bus." The bus can be an important private place in a public space.

Another way riders demonstrated resourcefulness was by strengthening social connections while in transit. Many participants used their mobile phones to request transit information, or to coordinate meeting places or routes with friends and family. Some used the unique identifier code on each bus to precisely coordinate meeting with friends along the route by letting them know which bus to board. Several riders mentioned the familiar faces that they see on a bus, and how these people help you. "When you take the bus often enough, you eventually make bus buddies-your new best friends. It's the bus buddies that will make the driver wait for you when you're crossing the street."

When making choices about transit options, the riders in our study had a variety of priorities, cost being the most important. Many riders mentioned recent fare increases and were concerned about being able to afford taking the bus. As a way to save money, riders chose to take routes that had lower fares, even if the cheaper routes were less direct and took longer. Other riders timed their commutes around off-peak times during the day and could save $\$ 0.25$ per ride.

Second after cost, reliability was an important priority. Transit dependent riders expressed frustration about buses that arrived late or not at all, and about buses that did not stop because they were too crowded. The distances that riders had to walk to bus stops also influenced their decision to take certain buses. Some riders, especially the sick and elderly, feared that long walks could harm their health; other riders preferred to walk a longer distance if they could catch a quicker bus or save money. Information services that suggest bus routes, like Google Transit, do 
not account for the terrain. A bus stop might be within walking distance and only .5 miles away, but at the top of a steep uphill. Some riders mentioned that when picking a route, saving time is a lower priority than saving money.

Figure 1 shows a photo from a video diary. The study participant talked about how few bus stops there are and how long he has to walk to the bus stop. He also talked about how, although there are good jobs in this neighborhood, those opportunities are out of reach for many people because of how difficult it is to get to there.

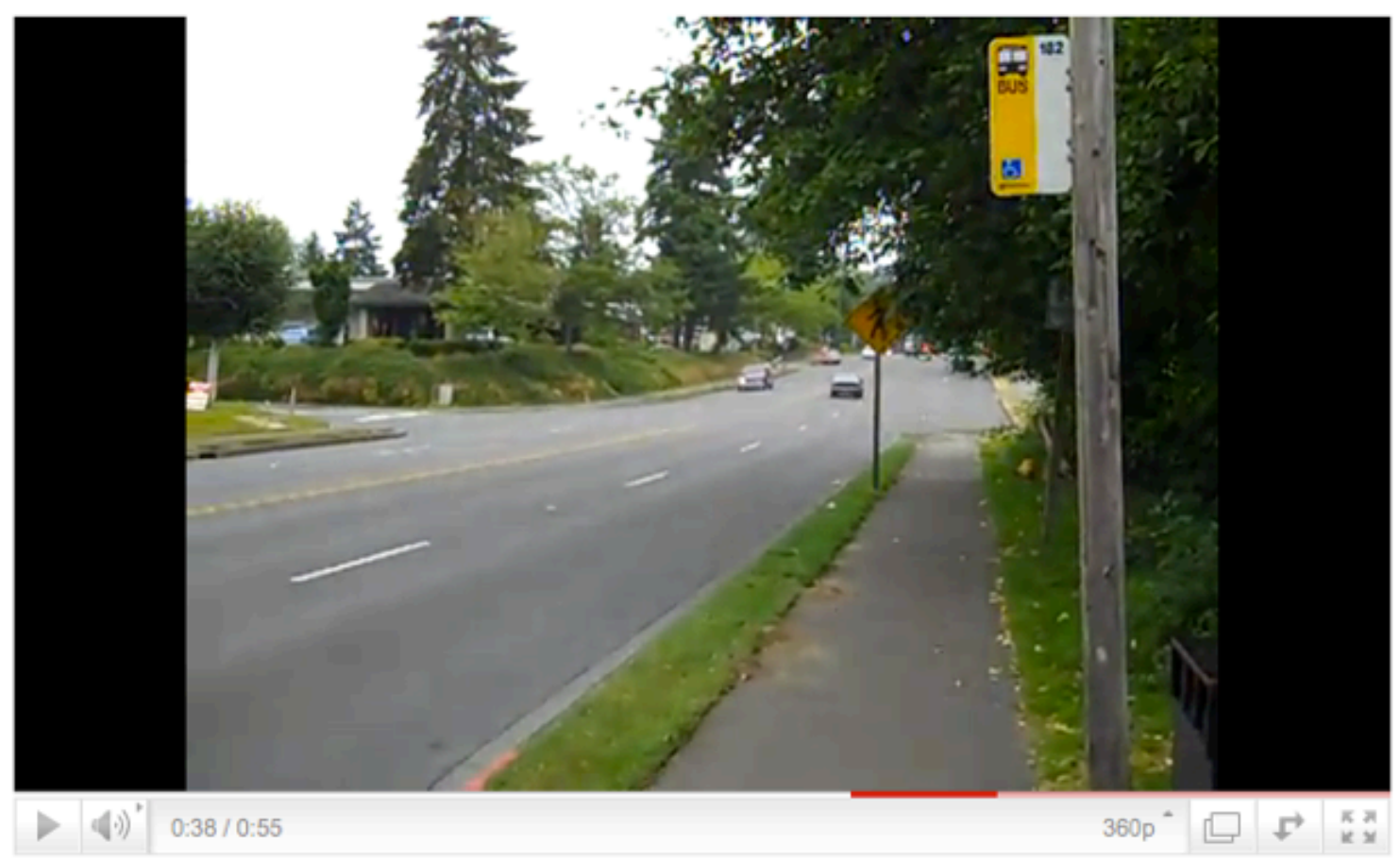

Figure 1: A video still from Eddy's video where he was talking about waiting for buses in Federal Way. The image shows a four lane road, a sidewalk and a bus stop.

\section{Resilience}

The second category of agency is what we call resilience. Resilience differs from resourcefulness in its relationship to structure. Resourceful acts utilize expertise of resources in a way that is sanctioned or approved within the existing structure. By contrast, acts of resilience fall outside of what the existing structures support and in some cases are acts that are unsanctioned or illegal. Oftentimes, riders choose to manipulate resources in order to overcome barriers and challenges.

When the transit system does not accommodate riders' needs, they often make concessions or improvise solutions. Participants mentioned instances where they took extreme measures to get where they needed to go. These situations occurred when the transit system did not run -- for example, during the late-night and early-morning hours -- and when bad weather (snow, for example) closed roads or interfered with service. One rider rode his bike 30 miles to work 
because no bus accommodated his early-morning shift at a fisheries plant. He mentioned that his long commute contributed to the challenges of being on time, which was one of the reasons his employment at the plant ended.

Other riders in our study used illegal or unsafe means - from avoiding fare payments, to stealing cars, to hitch-hiking - to overcome their transportation challenges. Fare avoidance was both varied and prevalent. Some riders paid an insufficient fare, while others jumped off the bus without paying. And some innovative riders saved their expired paper bus transfer tickets to reuse in the future. Bus transfers are marked with a letter and color combination, plus the expiration time (see Figure 2). "I save transfers. Every color, every letter. I learned how to do it in middle school. Then I text or call someone to find out about the transfer [color of the day]. I have between 20 and 30 of them in my collection. I have a friend who has a sandwich bag full of them. " Participants mentioned that although they occasionally absconded without paying the full fare, they usually were honest with the drivers, and appealed to their compassion. "I'm not asking to ride free all the time. Be considerate of a person's situation," said one participant. Participants said that many drivers are sympathetic and asked them to pay what they could afford.

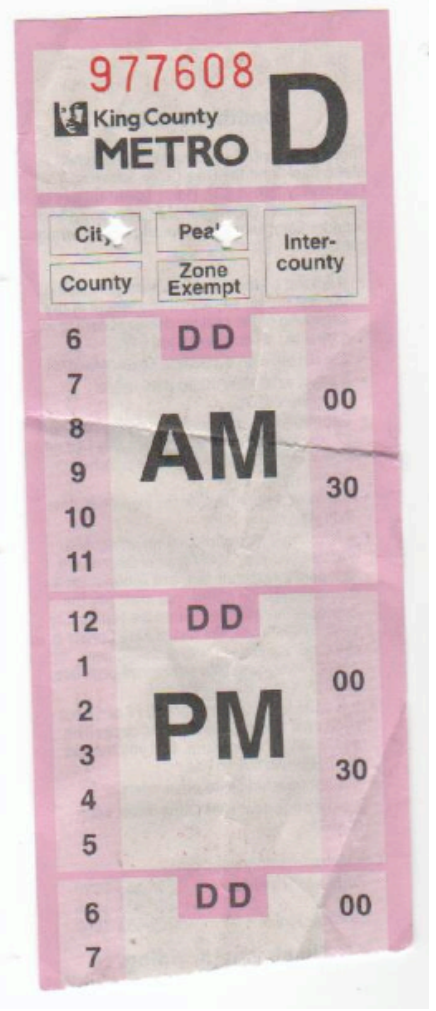

Figure 2: Paper transfer ticket. 


\section{Powerlessness}

The final category of agency is powerlessness, which is when a person is incapable of exerting agency on the structure at hand. In our study, powerlessness includes moments when riders lack choices because of constraints in the transit system, or because of how they are treated by others. In moments of powerlessness, riders express their feelings of fear, frustration, and defeat.

Riders worried about their safety when waiting for the bus at night or when they were alone in an unsafe area. On the bus, some riders worried about the aggressive behavior of other passengers. "Some routes are just not safe [and it's] frustrating because you just want to get home."

Riders in our study were often late to work or for appointments because of bus delays or a lack of bus routes that went where they were going. The delays and lack of service contributed to tardiness, which cost several riders their jobs. "I lost a client because of Metro. After the bus was considerably late, I had to call and cancel my appointment. They weren't interested in having someone cancel appointments. I wound up losing that account." Another participant turned down jobs because of transit limitations. "Being dependent upon the transit system, you kind of have to turn down jobs because the transit system doesn't get there, or by a certain time, or I could get there, but not get back." According to one participant, transit availability determined where he could live. While housing might be cheaper further out from the city, the transit options to and from the suburbs are more limited. "I wanted to go look at an apartment in Kent (an outlying suburb) but no buses went out there. The closest bus was four miles away.”

Participants in the study talked about the cost of riding the bus and how it was a significant expense to get where they needed to go. Figure 3 shows a still of Helen, who was reflecting on the cost of the trip across town for her and her niece.

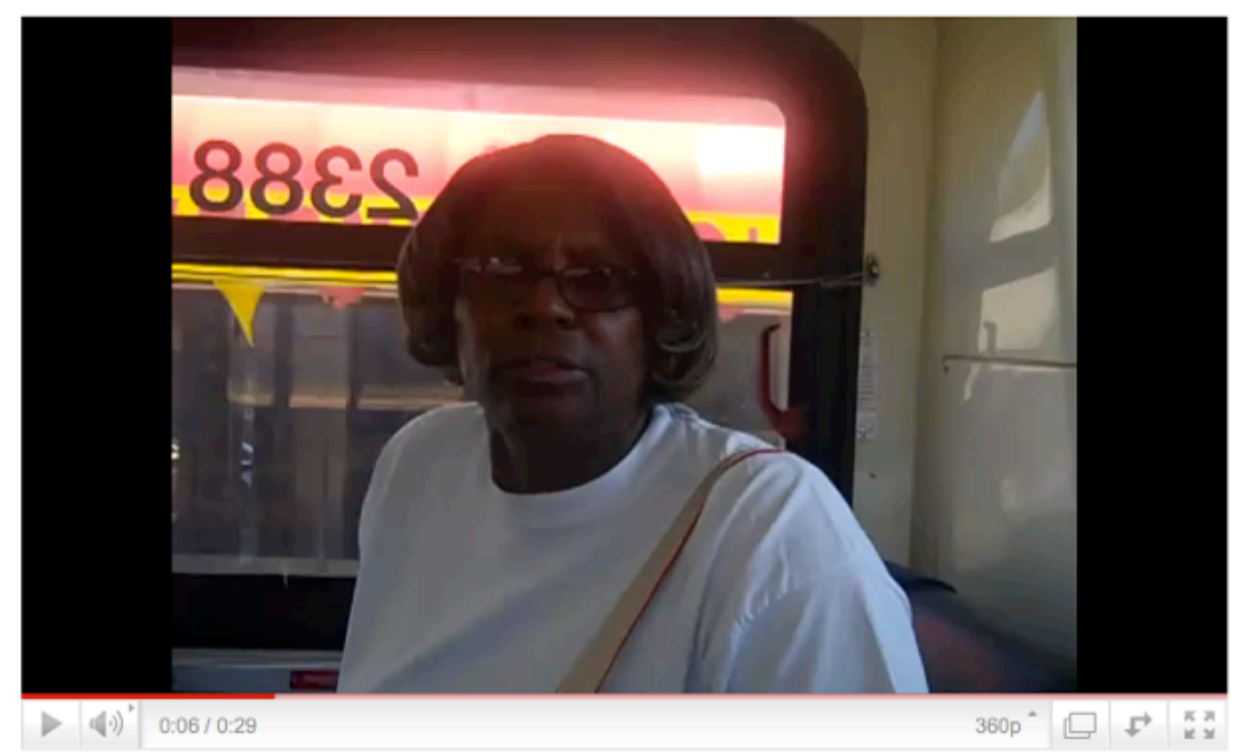

Figure 3: Video still from Helen and Monica's video diary talking about fares where Helen is talking about their long day using transit. 
The topic of respect came up for some riders. This was a particularly personal topic for the poorer or homeless participants that we spoke to. Riders in our study told stories about bus drivers and transit authorities treating them badly. Participants talked about buses that did not stop, sometimes because they were full, and other times for no obvious reason. The homeless riders believed that drivers did not respect them, and that was why they did not stop. "The way they treat me sometimes ... Drivers should treat [passengers] with respect. If you can't handle people in the public, get another job. They can be rude."

Others riders talked about when there were few transportation options, they might need to hitchhike and how dangerous that was. "I used to [hitchhike]. Luckily, I'm still around. There are some crazy people out there. I used to hitchhike from town to town. What I'd do is, I'd call a friend, and see if they can find me a ride where I need to go. If not, then I'd just take the bus and then have to walk."

Taken together, powerlessness combined with transit dependence reveals how limiting it can be not to have reliable access to transportation. A lack of reliable and accessible transit options constrains access to housing and jobs, and has a further negative effect on personal feelings of safety and belonging.

\section{Discussion}

In this section, we use the findings from our study and the theoretical framework of structuration to examine the designs of ICTs and policies that support riders. The first is the fare collection system called ORCA. We look at the design that was implemented and how this design intentionally and unintentionally reduced transit dependent riders' agency. The second series of recommendations is related to transit policies and how ICTS are designed.

\section{Fare collection system: The ORCA card}

At the time of our study, transit authorities in the Puget Sound region had started to transition from cash payments and paper transfers to the use of a regional fare pass called ORCA (One Regional Card for All). The purpose of this new system was to streamline fares across seven transit agencies in the Puget Sound region. While the transit agencies still accepted cash, they encouraged riders to use an ORCA card instead. The ORCA card as a fare pass is a growing trend and many urban transit systems are adopting similar smart card systems. The adoption of smart card systems provides a number of benefits for transit agencies and riders (Pelletier, Trépanier, \& Morency, 2011), (Iseki, et al., 2008). For transit agencies, smart cards streamline fare collection, and they provide a wealth of rider information like travel patterns and the impact to ridership because of schedule and route changes (Pelletier et al., 2011). For riders, the benefits include a more convenient way to purchase and pay for transit (Iseki, et al., 2008).

Based on our findings, we see how the ORCA smart card benefits the transit service by restricting and constraining agentive acts that were present before the implementation of this system. The ORCA card costs $\$ 5$ to purchase, which can be a barrier for low-income riders. 
Because riders fund the ORCA card instead of paying with their loose change, the exact fare is deducted when the rider taps the card on the card reader. Some riders cannot afford to pay the full fare all the time, so they pay what they can and then appeal to the driver's compassion to settle the difference. The ORCA card hampers this kind of negotiation, disempowering both the rider and the driver. Whereas with loose change riders could pay for some of their fare, with the ORCA card they must pay the entire fare or none of it.

The largest implication for the adoption of the ORCA card system is the movement away from paper transfers to an electronic transfer system. Currently, when riders pay cash they receive a paper transfer that specifies how long they can ride other buses before they must pay for a new fare (see Figure 2). The results of this study showed the important role that paper transfers play for transit dependent riders. For example, riders use transfers to structure their time, meaning that if they have a generous transfer with time to spare, they might explore the area or run extra errands. With the ORCA card, transfers are recorded electronically; riders no longer receive printed receipts that say when a transfer expires. Transfer information is available online, but it is not always accessible or accurate. The ORCA system does not always record transfer information in real time. To view their ORCA accounts, riders must have access to the Internet during their ride, which excludes most transit dependent riders. The way the system is designed, the inability to access transfer information puts the rider at a disadvantage. In a design where the information needs of the riders were considered, transfer information would be up-to-date and easier to access. Perhaps instead of requiring Internet access, riders could sign up to receive SMS text alerts that inform them about when the transfer was given and how much time they have remaining before the transfer expires.

The ORCA website (http://www.orcacard.com) is not optimized for a mobile experience, resulting in a variety of usability problems. Without a paper transfer or access to the ORCA system, riders do not have a reminder of how long they have left to transfer without paying for another ride. When using the ORCA card, riders tap a card reader each time they enter the bus. They only know that a transfer has expired when they are charged a new fare. Unable to know how much time is left on a transfer, riders lose some of their agency: they cannot make informed decisions about their travel plans and are not given a chance to either choose not to ride or appeal to the driver's compassion if they cannot pay the full fare. We heard from riders that paying an additional \$2.25 fare is not always possible. Given the option to pay a new fare or walk, some riders would rather walk to save money.

Looking at the implementation of this technology through the lens of structuration, it is clear that the transit policy makers, agencies, and drivers may be invested in reducing fare evasion in order to maintain services and staffing as local governments face unprecedented deficits in the current economy. For example, King County Metro estimates that they lose up to \$3.4 million per year, or $2.4 \%$ of total revenue, because of fare evasion. Looking at fare evasion in the light of structuration, we see that when riders evade fares this can lead to revenue loss for the transit agency. We strive to look for solutions that can continue to promote rider agency without exacerbating fare evasion. 
The ORCA card addresses fare evasion, but at the expense of a riders' agency: requiring an exact fare and obscuring transfer information limits the choices that riders and drivers can make. To give riders the information that they require, the ORCA card could support SMS messaging. Most of the riders had mobile phones, though not all of them had Internet-enabled smartphones. Instead of requiring an Internet connection to look up transfer information, a rider could receive a text message 15 minutes or 30 minutes before a transfer expires. Mentioned previously, transit dependent riders rely heavily on mobile phones and text messaging. Also mentioned, small amounts of money are important to low-income riders. Instead of paying a full fare to travel only a few miles, riders could send a text message to the ORCA system, purchasing an extra 30 minutes for $\$ 0.25$. Creating an SMS system to access ORCA information would be helpful not just for transfers, but for other transactions including checking balances and adding money to an account when linked to mobile banking capabilities.

\section{Relationship of agency and expertise}

In the findings from this study, we have provided a variety of examples that support a layered understanding of agency in the categories of resourcefulness, resilience and powerlessness. Individuals can take action to bring about results based on access to resources and adhering to, or ignoring, structures, social norms and sanctions. In addition, as knowledgeable agents in the world, the people in our study had developed these strategies and tactics in order to overcome transportation constraints. They use their expertise, which is developed through personal experience, trial and error, and being situated within larger communities of practice (Lave \& Wenger, 1991). The expert behaviors that are exhibited by the people who participated in this study reflect their own practices and those of others in the community and are passed on to others explicitly or implicitly by enculturation. For example, the practice of saving transfer tickets was a practice that a person in our study claimed that she learned in middle school. Thinking of these acts as being expert in nature, rather than as base or unwanted acts or as examples of people merely getting on in the world, allows us to see opportunities for design in a different light. For example, small amounts of money are important to transit dependent riders. How does that information help designers think differently about fare systems, fare policies, and the ICTs that enforce them? By thinking of these practices as expertise rather than as scamming the system, we see people's needs in a different light. When vulnerable populations, such as the homeless bus riders in the study, come up with ways to meet their needs and preserve the human value of dignity, we can see the need to ride the bus in a different way. Privileging agentive acts as acts of expertise, helps to illuminate the ways in which systems can be designed and designed differently.

\section{Taking a human centered design approach}

Based on the evidence from the study, including contextual factors that are identified through qualitative methods like ethnography, interviews and video diaries, it is clear that current ICTs that support transit do not account for the needs or practices of transit dependent riders. To do so, we recommend a shift in design strategy that keeps the needs of the transit agencies in balance 
with the needs of the communities and individuals they serve. Human centered design (which also overlaps with user-centered design) is a philosophy and process that is used to design ICTs. Human centered design contains three components: an early focus on users and their needs, empirical data and iterative design (Gould and Lewis, 1985). Philosophically, the human centered approach believes that a system cannot succeed unless the needs of the people who use the system are the key drivers for design (Norman and Draper, 1986). While human centered design is an accepted approach in many disciplines, most notably in the development of ICTs, it is also used in developing solutions for educators, non-profits, and community groups. Using human-centered design in transportation and urban planning is less common.

The findings of this study suggest that the needs of transit dependent users have been overlooked. Human centered design, with its early focus on users and their goals, empirical measurement, scalability and iterative design process, can help create ICTs that maximize choice, balance the needs of users and transit agencies, and reduce unintended consequences.

Human centered design, according to Buchanan, is "not a rejection of function, but a recognition that unless designers grasp the significant content of the product they create, their work will come to little consequence or may even lead to harm in our complex world" (2001, p. 35). Therefore, how is it that designers can see or account for the ways in which design can be done differently? How can researchers, activities and community members that are interested in community informatics more fully engage with the design of information and communication technologies, and from the start of the design process investigate and account for community members needs, especially with regard to marginalized or vulnerable groups?

Participatory design is a conceptually and historically related approach, and well known in the informatics community (see Carroll and Rosson 2007). However, we see very little participatory design that is practiced at the community level in our experience working with community partners in North America. From our experience engaging in community planning, much work in the community is done to include communities in the decision making process including holding open meetings to discuss policy changes and including diverse community group and their representatives. However, we would continue to advocate for and investigate ways that design can also be a process and practice to include and engage communities. As Buchanan states, "Human-centered design is fundamentally an affirmation of human dignity. It is an ongoing search for what can be done to support and strengthen the dignity of human beings as they act out their lives in varied social, economic, political and cultural circumstances" (2001, p.37).

\section{Implications and conclusion}

The portraits of the transit dependent are diverse and complex. We spoke with riders who were homeless, unemployed, disabled, or in recovery. The majority of participants were low-income. Because of their marginal status in society and the fewer options they have in accessing social networks, goods, and services, the transit dependent are at risk of mobility-related social exclusion, or the inability to participate in the political, economic, and social life of their 
communities. But while they are marginalized, transit dependent audiences demonstrate sophisticated expertise of the transit system. Learning about their resilient use of transfers pointed out design flaws in the ORCA card system. Hearing about the importance of social life on the bus allows us to consider how to combine social software with location. Thinking about the priorities of transit dependent riders allows us to think about values that go beyond the efficiency of bus routes, like taking a bus ride for sanctuary or for the joy of discovering new parts of the city. These are expert behaviors exhibited by the transit dependent. Paying attention to their strategies in a systematic way, through the human centered design process, can help public service providers, technologists and community planners think differently about the ways systems are designed. Design improvements based on the expertise of transit dependent riders can also benefit all riders at the same time.

As a result of this research, we developed a set of heuristics or guiding questions that can inform the research and design of information and communication technologies in community informatics. Table 3 shows each agentive category paired with questions to guide research and design of ICTs.

Table 3. Heuristics for considering agency when designing ICTs

\begin{tabular}{|c|c|c|}
\hline & Questions for research & Questions for design \\
\hline Resourcefulness & $\begin{array}{l}\text { 1. How do expert users overcome a } \\
\text { system's limitations? } \\
\text { 2. How do expert users exploit their } \\
\text { knowledge to bring about desired } \\
\text { results? }\end{array}$ & $\begin{array}{l}\text { 1. How can the design support } \\
\text { expertise? } \\
\text { 2. How can the expertise of others be } \\
\text { designed into the systems or } \\
\text { revealed to all users? }\end{array}$ \\
\hline Resilience & $\begin{array}{l}\text { 1. What strategies and tactics do } \\
\text { users employ when a system does } \\
\text { not meet their needs? } \\
\text { 2. How do users overcome system } \\
\text { constraints in unsanctioned or } \\
\text { unsupported ways? } \\
\text { 3. How do users conceptualize } \\
\text { unsanctioned acts? What are the } \\
\text { values that support or suppress } \\
\text { these acts? } \\
\text { 4. How would users be impacted if } \\
\text { their resilient acts were prevented } \\
\text { by a change to the system? }\end{array}$ & $\begin{array}{l}\text { 1. How can systems be designed to } \\
\text { help people overcome constraints } \\
\text { in a way that supports their goals? } \\
\text { 2. How will design changes or } \\
\text { decisions unearth or foreclose } \\
\text { unsanctioned behavior? What are } \\
\text { the consequences of doing so? } \\
\text { 3. In what ways can systems be } \\
\text { designed to enable opportunities } \\
\text { for users to make decisions that } \\
\text { support key goals or values? }\end{array}$ \\
\hline Powerlessness & $\begin{array}{l}\text { 1. How do systems reduce a person's } \\
\text { ability to act? } \\
\text { 2. What are the consequences when } \\
\text { systems do not work in ways that } \\
\text { match users' needs? } \\
\text { 3. How do changes in systems impact } \\
\text { users' abilities to achieve their } \\
\text { goals? }\end{array}$ & $\begin{array}{l}\text { 1. How can systems be designed to } \\
\text { provide a variety of options for } \\
\text { users? } \\
\text { 2. In what ways can the system be } \\
\text { designed to empower users? } \\
\text { 3. How can changes to design } \\
\text { provide more (or less) autonomy } \\
\text { or freedom? }\end{array}$ \\
\hline
\end{tabular}


Community informatics has continued to focus on the needs of diverse communities and how these needs translate into policies and technologies that are equitable and inclusive. Continuing to look at the design of the mundane systems and services that impact people's daily lives is a way to attend to the lived experiences of individuals and communities with the goal of creating more equitable solutions. In addition, using the guiding heuristics can help designers and developers of systems consider how they may enable or constrain the agency of individuals and groups in their communities.

In Le Dantec and Edward's study examining technology use and homeless populations, they reflect on the role and responsibility of system designers (2008). They reflect that designers must take into account the social impact new technologies have on users and non users so as not to create "an even larger rift between ourselves" (p. 633) and those we are designing for, especially in case of marginalized populations (Le Dantec \& Edwards, 2008). Addressing the challenges of the transit dependent requires a variety of approaches. While we believe our research can inform technological solutions that contribute to transit solutions, we acknowledge that for our solutions to have the greatest impact, they must accompany or support shifts in policy and social thinking as well. 


\section{References}

Aalbers, M. B. (2006). 'When the banks withdraw, slum landlords take over': The structuration of neighbourhood decline through redlining, drug dealing, speculation and immigrant exploitation. Urban Studies, 43(7), 1061-1086.

Anderson, L. (2006). Analytic Autoethnography. Journal of Contemporary Ethnography 35(4): $373-395$.

Atkinson, P., \& Hammersley, M., (1994). Ethnography and participant observation. in Handbook of qualitative research Ed. N.K. Denzin \& Y.S. Lincoln pp. 248-261. Thousand Oaks, CA, US: Sage Publications.

Beimborn E, Greenwald, M., \& Jin, X. (2003). Accessibility, Connectivity, and Captivity: Impacts on Transit Choice. Transportation Research Record: Journal of the Transportation Research Board 1835: 1-9.

Bell, G., Blythe, M. \& Sengers, P. (2005). Making by making strange: Defamiliarization and the design of domestic technologies. Transactions on Computer-Human Interaction (TOCHI 12(2).

Booth, D., Hanmer, L. \& Lovell, E. (2000). Poverty and transport: a report prepared for the World Bank in collaboration with DFID. London: Overseas Development Institute.

Brabo, L.M., Kilde, P.H., \& Pesek-Herriges, P., et al. (2003). Driving Out of Poverty in Private Automobiles. Journal of Poverty 7(1-2): 183-196.

Bradbury A. (2006). Transport, mobility and social capital in developing countries. Engineering Sustainability 159(2): 79-86.

Buchanan, R. (2001). Human dignity and human rights: Thoughts on the principles of humancentered design. Design issues, 17(3), 35-39.

Bullard, R. D. (2003). Addressing urban transportation equity in the United States. Fordham Urb. $L J, 31,1183$.

Carroll, J. M., \& Rosson, M. B. (2007). Participatory design in community informatics. Design studies, 28(3), 243-261.

Chavez V. (2004). A Bridge between Communities: Video-Making Using Principles of CommunityBased Participatory Research. Health Promotion Practice 5(4): 395-403.

Coffey, A., \& Atkinson, P. (1996). Making sense of qualitative data: Complementary research strategies. Thousand Oaks, CA: Sage Publications, Inc.

Ferris, B., Watkins, K., \& Borning, A. (2010a). Location-aware tools for improving public transit usability. IEEE Pervasive Computing, 9(1), 13-19.

Ferris, B., Watkins, K., \& Borning, A. (2010b). OneBusAway: results from providing real-time arrival information for public transit. In Proceedings of the SIGCHI Conference on Human Factors in Computing Systems (pp. 1807-1816). ACM.

Ferguson, E. M., Duthie, J., Unnikrishnan, A., \& Waller, S. T. (2012). Incorporating equity into the transit frequency-setting problem. Transportation Research Part A: Policy and Practice, 46(1), 
190-199.

Garrett, M., \& Taylor, B. (1999). Reconsidering social equity in public transit. Berkeley Planning Journal, 13(1).

Giddens, A. (1984). The constitution of society: Outline of the theory of structuration. Univ of California Press: Oakland, C.

Gould, J.D. \& Lewis, C. (1985). Designing for usability: key principles and what designers think. Communications of the ACM, ACM 28(3).

Gurstein, M. (2003). Effective use: A community informatics strategy beyond the digital divide. First Monday, 8(12).

Gurstein, M. (2015). Why I'm giving up on the digital divide. The Journal of Community Informatics, 11(1).

Giuliano, G, (2015). Low income, public transit, and mobility. Transportation Research Record: Journal of the Transportation Research Board 1927: 63-70.

Iseki, H., Demisch, A., Taylor, B. D., \& Yoh, A. (2008). Evaluating the costs and benefits of transit smart cards. Berkeley: California PATH Program, Institute of Transportation Studies, University of California.

Krizek, K. J., \& El-Geneidy, A. (2007). Segmenting preferences and habits of transit users and nonusers. Journal of public transportation, 10(3), 5.

Lave, J., \& Wenger, E. (1991). Situated learning: Legitimate peripheral participation. Cambridge university press.

Le Dantec, C.A. \& Edwards W.K. (2008). Designs on dignity: perceptions of technology among the homeless. Proceeding of the twenty-sixth annual CHI conference, New York, New York, USA: ACM.

McQuarrie, M., \& Marwell, N. P. (2009). The missing organizational dimension in urban sociology. City \& Community, 8(3), 247-268.

Norman, D. A., \& Draper, S. W. (1986). User centered system design. New Perspectives on HumanComputer Interaction, L. Erlbaum Associates Inc., Hillsdale, NJ, 3.

Pelletier, M. P., Trépanier, M., \& Morency, C. (2011). Smart card data use in public transit: A literature review. Transportation Research Part C: Emerging Technologies, 19(4), 557-568.

Polzin, S., Chu, X., \& Rey, J. (2000). Density and captivity in public transit success: observations from the 1995 nationwide personal transportation study. Transportation Research Record: Journal of the Transportation Research Board, (1735), 10-18.

Pratt, A.C. (1996). Coordinating Employment, Transport and Housing in Cities: An Institutional Perspective. Urban studies, SAGE Publications 33(8): 1357-1375.

Rose, E. J. (2011). Investigating resource-constrained populations: Developing design approaches to support agency and reciprocity (doctoral dissertation), ProQuest Dissertations and Theses.

Rittner, B., \& Kirk, A. B. (1995). Health care and public transportation use by poor and frail elderly 
people. Social work, 40(3), 365-373.

Salvador, T., Bell, G. \& Anderson, K. (1999) Design Ethnography. Design Management Journal, Blackwell Publishing Ltd 10(4): 35-41.

Sanchez, T.W. (2008). Poverty, policy, and public transportation. Transportation Research Part A: Policy and Practice 42(5): 833-841.

Staffans, A., \& Horelli, L. (2014). Expanded urban planning as a vehicle for understanding and shaping smart, liveable cities. The Journal of Community Informatics, 10(3).

Taylor, P.S. (2009). The Road Out of Poverty: Lowering barriers to employment through automobile ownership. Frontier Centre for Public Policy: Policy Series (71): 1-25.

Wang, C., \& Burris, M. A. (1997). Photovoice: Concept, methodology, and use for participatory needs assessment. Health education \& behavior, 24(3), 369-387. 